\title{
Quality of life after stapler haemorrhoidectomy evaluated by SF-36 questionnaire
}

\author{
Ahmet Erdoğdu ${ }^{1}$, Nurver Turfaner Sipahioğlu', Ethem Erginöz², Berat Apaydın³, Fikret Sipahioğlu
}

\section{ABSTRACT}

'Department of Family Medicine, İstanbul University Cerrahpaşa Faculty of Medicine, İtanbul, Turkey ${ }^{2}$ Department of Public Health, İstanbul University Cerrahpaşa Faculty of Medicine, Istanbul, Turkey ${ }^{3}$ Department of General Surgery, İstanbul University Cerrahpaşa Faculty of Medicine, İstanbul, Turkey ${ }^{4}$ Departmet of Internal Medicine, İstanbul University Cerrahpaşa Faculty of Medicine, Istanbul, Turkey

This study was presented as a poster in WONCA Europe 3-7 (July 2012, Wien, Austria)

\section{Address for Correspondence}

Dr. Nurver Turfaner Sipahioğlu Department of Family Medicine, İstanbul University Cerrahpaşa Faculty of Medicine, İstanbul, Turkey

Phone.: +9053249617 73

e-mail:

nurver@doctor.com

Received: 02.04 .2013

Accepted: 19.05.2013

(C) Copyright 2013 by Turkish Surgical Association

Available online at www.ulusalcerrahidergisi.org
Objective: Hemorrhoids are normal elements of the anal canal anatomy and they become symptomatic with potential factors such as gravity or strain. When symptomatic, hemorrhoidal disease can be costly measured in time away from productive activities. The aim of the study was to assess changes in the quality of life of patients after hemorrhoidectomy using Short Form-36.

Material and Methods: Thirty patients, 24 male and 6 female (age 28 to 65), who were diagnosed with grade III and IV internal hemorrhoidal disease at the general surgery outpatient clinic and treated with stapled hemorrhoidectomy were enrolled in the study. They filled out Short Form-36 a week before surgery and four weeks after surgery. Post-Hoc tests were evaluated with Bonferroni correction after Kruskal Wallis analysis. Wilcoxon test, Student-t-test and Mann-Whitney $\mathrm{U}$ test were used for statistical analysis using SPSS 15.

Results: Physical health (Physical functioning, Physical role restriction, Bodily pain) scores were significantly improved after surgery. Conclusion: Success of hemorrhoidectomy operations can be evaluated by postoperative recovery, incidence of complications or relapses. Quality of life questionnaires are another method to evaluate the success of the treatment from the patient's perspective.

Key Words: Hemorrhoidectomy, quality of life, Short Form-36

\section{INTRODUCTION}

Hemorrhoidal disease is a frequent disease of the anal canal.

Hemorrhoids are important vascular cushions located in the anal canal as part of the normal anatomy. These cushions are composed of arteries, veins, smooth muscle fibers and connective tissue embedded in thickened submucosa (1).

They are located in three main positions; left lateral, right anterior and right posterior. Internal hemorrhoids are located above the dentate line and external hemorrhoids are located in the distal part of the dentate line. The etiology is not clear, within some factors are gravity, straining, irregular bowel habits. Other causes are pregnancy, birth, spicy food, chronic cough, obesity, alcohol, benign prostate hyperplasia, cirrhosis, intra-abdominal tumors and some activities that require long periods of immobility $(2,3)$.

Many surgical techniques are applied for the treatment of hemorrhoidal disease. It is widely accepted to treat grade 1 and 2 patients medically (diet and medication) and minor procedures (band ligation, sclerotherapy) and grade 3 and 4 patients with surgery $(2,4,5)$.

Currently stapled hemorrhoidopexy is the preferred technique by patients, due to decreased postoperative pain and other complications, and shorter length of hospital stay (6-8). The success and efficacy of hemorrhoidectomy procedures can be evaluated based on postoperative healing duration, complications and recurrence as well as questionnaires that reveal patient's perspective.

Short Form-36 (SF-36) is distinguished from other scales (Nottingham Health Profile) by being a selfassessment scale that is easily filled by the patient in a short time, evaluating the positive sides of the health status as well as the negative sides and detecting minor changes in disability (9).

The form contains 36 items which evaluate 8 health dimensions; physical function (10 item), social function ( 2 item), role limitations due to physical problems (4 item), role limitations due to emotional problems( 3 item), mental health (5 item), energy/vitality (4 item), pain ( 2 item) and general perception 
of health (5 item). Sub-scales evaluate quality of life from 0 to 100 , where 0 indicates the worst health status and 100 the best (10-12).

This prospective study aimed to determine postoperative quality of life in patients undergoing surgery for grade 3 and 4 hemorrhoidal disease using SF-36.

\section{MATERIAL AND METHODS}

The study included 30 patients who presented to Istanbul University Cerrahpasa Medical Faculty Department of General Surgery with anal region complaints and were diagnosed with grade 3 or 4 internal hemorrhoidal disease after evaluation by examination, rectosigmoidoscopy or other methods. Patients with concomitant pathologies were excluded. SF-36 questionnaire was applied to all patients face to face during the week prior to surgery. The second form was filled in the $4^{\text {th }}$ postoperative week over the telephone. Informed consent was obtained from all patients. The Ethical Board of Istanbul University Cerrahpaşa Medical Faculty approved the study on 5 April 2011, under the number of 12819.

The surgical technique applied in all patients was stapled hemorrhoidectomy. The patients' age were between, there were 28 and 65 mean: (42.63 \pm 9.65$)$. Six patients were female (20\%), and, 24 were male (80\%). When stratified according to level of education, there were 6 primary school graduates (20\%), 15 high school graduates (50\%), and 9 university graduates (30\%). When the occupational status was evaluated, 5 had never worked before (16.7\%), 8 were retired (26.7\%), and 17 were actively working (56.7\%). Table 1 lists the demographic data.

\section{Statistical Analysis}

All statistics were done by Statistical Packages for the Social Sciences (SPSS) 15,0 for Windows program. Post-Hoc tests were evaluated with Bonferroni correction after Kruskal Wallis analysis, Wilcoxon test, Student-t-test and Mann-Whitney U test.

\section{RESULTS}

Preoperative and postoperative SF-36 scores of the patients enrolled in the study were compared. This comparison revealed a statistically significant difference in pre and post operative physical function, physical role and pain scores $(p<0.01)$. In the postoperative period, physical functions showed a significant increase, and physical role limitation and pain showed a significant decrease.

The remaining sub-groups on SF-36 scale did not show a statistically significant difference between initial test and final test scores ( $p>0.05)$ (Table 2).

The preoperative SF-36 scores were compared according to gender. Female patients revealed a higher score on vitality/ energy than male patients $(p<0.05)$.

When preoperative SF-36 scores were compared with regards to age, mental health $(p<0.05)$ and physical role limitation
The pain scores in the postoperative SF-36 test were significantly higher in females than in males $(p<0.05)$.

The postoperative SF-36 scores of patients were compared with regards to level of education. The pain dimension of SF36 scale showed a statistically significant difference according to education $(p<0.05)$. A Post-Hoc Bonferroni correction analysis which was done to reveal in which groups this difference existed demonstrated that, primary school graduates had significantly higher pain scores than high school and university graduates $(p=0.016, p=0.007)$.

The pain scores between the high school and university graduates did not show a statistically significant difference ( $p>0.05)$.

The mental health scores of the postoperative SF-36 scale decreased as patients age increased $(p=0.01)$. Table 3 lists these results.

\section{DISCUSSION}

Hemorrhoidal disease has a negative effect on daily activities and leads to loss of resources. Nevertheless, publications on the relationship of hemorrhoidal disease and quality of life date back to 1998. Recent studies focus on the surgical techniques used and their effects on quality of life after treat-

Table 1. Socio-demographic findings of patients evaluated by SF-36

\begin{tabular}{|lccc|}
\hline \multirow{3}{*}{ Gender } & & N & $\%$ \\
\hline \multirow{3}{*}{ Education } & Female & 6 & 20 \\
& Male & 24 & 80 \\
\hline \multirow{3}{*}{ Occupancy } & High school & 15 & 50 \\
& University & 9 & 30 \\
& Unemployed & 5 & 17 \\
& Retired & 8 & 27 \\
\hline & Actively working & 17 & 56 \\
\hline
\end{tabular}

Table 2. Comparison of pre- and post-operative SF-36 scores

\begin{tabular}{|l|ccc|}
\hline & \multicolumn{1}{c}{$\begin{array}{c}\text { Pre-op } \\
\text { mean } \pm \text { SD }\end{array}$} & $\begin{array}{c}\text { Post-op } \\
\text { mean } \pm \text { SD }\end{array}$ & $p$ \\
\hline Sf-36 Sub-groups & & & \\
\hline Physical function & $66.00 \pm 20.73$ & $76.83 \pm 10.78$ & $<0.001^{*}$ \\
\hline Physical role limitation & $30.00 \pm 37.94$ & 0 & $<0.001^{*}$ \\
\hline Pain & $43.3 \pm 17.6$ & $35.9 \pm 9.9$ & $0.007^{*}$ \\
\hline General health & $49.83 \pm 6.36$ & $48.16 \pm 5,33$ & 0.316 \\
\hline Vitality (energy) & $59.83 \pm 7.36$ & $59.66 \pm 5.71$ & 0.885 \\
\hline Social function & $47.50 \pm 6.05$ & $50.83 \pm 6.51$ & 0.07 \\
\hline Emotional role limitation & $75.55 \pm 31.48$ & $71.11 \pm 32.44$ & 0.471 \\
\hline Mental health & $58.80 \pm 8.07$ & $60.66 \pm 5.56$ & 0.105 \\
\hline
\end{tabular}

Wilcoxon signed rank test, ${ }^{*} \mathrm{p}<0.01$ 
Table 3. Pre- and post-operative comparison of SF-36 subgroups according to socio-demographic variables

\begin{tabular}{|c|c|c|c|c|c|c|c|c|}
\hline \multirow{2}{*}{$\begin{array}{l}\mathrm{n}=30 \\
\text { SF-36 sub-group }\end{array}$} & \multicolumn{2}{|c|}{ Age } & \multicolumn{2}{|c|}{ Gender } & \multicolumn{2}{|c|}{ Education } & \multicolumn{2}{|c|}{ Occupancy } \\
\hline & Pre & Post & Pre & Post & Pre & Post & Pre & Post \\
\hline \multicolumn{9}{|l|}{ Physical function } \\
\hline Physical role limitation & 0.015 & & & & & & & \\
\hline Pain & & & & 0.027 & & 0.020 & & \\
\hline Vitality & & & 0.024 & & & & & \\
\hline Mental health & 0.037 & 0.01 & & & & & & \\
\hline
\end{tabular}

ment of hemorrhoidal disease. The number of patients who choose surgery is increasing due to the facts that surgical procedures are easily applied, with a short length of hospital stay and significant improvement in the quality of life (13).

Previous studies have shown that out of patients diagnosed with grade 3 or 4 internal hemorrhoids $42 \%$ had limitations in physical activities, $38 \%$ had significant reduction in social activities, and $8 \%$ in working activities (14).

In this study patients who claimed to limit the time they spare for daily work-related or other activities and who could not finish their tasks in time in the preoperative period showed a statistically significant improvement in their physical role limitation in the $4^{\text {th }}$ postoperative week $(p=0.001)$. Postoperative increase in physical functions $(p=0.001)$ and decrease in pain $(p=0.008)$ were also statistically significant. The other sub-groups of SF-36 scale did not show a statistically significant difference between their initial and final test scores $(p>0.05)$.

Khan et al. (15) compared excisional hemorrhoidectomy with harmonic scalpel hemorrhoidectomy in 2001 using SF-36 scale and found a significant increase in physical function and a significant decrease in pain and physical role limitation in both techniques. Different from our study, they also showed a significant increase related to social functions.

Martinson et al. (16) evaluated quality of life by SF-36 in the postoperative $6^{\text {th }}$ week and $6^{\text {th }}$ month in groups of conventional hemorrhoidectomy and stapled anopexia (PPH), and reported decrease in the PPH group and increase in the conventional hemorrhoidectomy group in certain dimensions (physical function, vitality, social function, mental health) after 6 weeks. The $6^{\text {th }}$ month results demonstrated significant increase in physical role limitation, pain, general health, social function and mental health parameters in the PPH group as compared to the conventional hemorrhoidectomy group.

Czarsky et al. (17) evaluated patients with grade III and grade IV hemorrhoidal disease who underwent stapled hemorrhoidopexy by QLQ-C30 on days 1 and 7, 4 weeks and 6 months. They have seen a decrease in the quality of life in the first days, a quick recovery after first week (50\%) reaching the plateau after a month (80\%). Pain and bleeding were the main problems.
In this study, changes in quality of life before and after hemorrhoidectomy were evaluated according to patient age, gender, educational and occupational status.

When pre-operative SF-36 scores were stratified according to age, physical role limitation was lower in the elderly. This is assumed to be the result of high physical expectations of the younger patients.

Pre- and postoperative mental health scores decreased with increasing age and this finding is in parallel to epidemiologic studies regarding the elderly.

Occupational status did not have an effect on postoperative quality of life. However, patients with lower education and females exerted significantly higher postoperative pain scores. In other words, female gender and less-education are risk factors for increase in postoperative pain perception.

Behboo et al. (18) reported that postoperative resting pressure $(p=0.74, p<0.01)$, squeezing pressure $(p=0.64, p=0.01)$ and maximum tolerable volume showed a significant correlation with female gender, in 33 patients who underwent stapled hemorrhoidopexy for grade II and III hemorrhoids. The high postoperative pain scores found in our study in female patients might be related to this situation.

Bussen et al. (19), in their study made an analysis of the studies regarding quality of life in hemorrhoidal disease and its treatment and concluded that especially postoperative data were insufficient.

In this study, other pre and postoperative sub-groups of SF-36 scale did not show any difference. These findings are in accordance with epidemiologic data on hemorrhoidal disease.

\section{CONCLUSION}

Hemorrhoidal disease is a condition that effects daily activities profoundly and leads to work leave and loss of performance. The quality of life in patients undergoing hemorrhoidectomy is increasing with improvements in surgical technique, less, postoperative complications and shorter length of hospital stay (6, $7,15-17)$. In this study there was an increase in the postoperative physical functions $(p<0.01)$ and decrease in, physical role limitation and pain perception $(p<0.01)$ in patients who underwent stapled hemorrhoidectomy for hemorrhoidal disease. 
Studies including larger patient population and with longer follow-up periods, like postoperative $6^{\text {th }}$ and $12^{\text {th }}$ months might provide more information on the quality of life after hemorrhoidectomy. The studies should include patients who are operated with same surgical technique, and the preoperative and postoperative test should be applied by the same group, thus creating more reliable results on postoperative quality of life in terms of demographic and social properties like age, gender, education and habits.

Ethics Committee Approval: Ethics committee approval was received for this study from the ethics committee of Istanbul University Cerrahpaşa Medical Faculty (05.04.2011, 12819).

Informed Consent: Written informed consent was obtained from patients who participated in this study.

Peer-review: Externally peer-reviewed.

Author Contributions: Concept - N.T.S., B.A.; Design - E.E.; Supervision - F.S., E.E., N.T.S.; Funding - F.S., B.A.; Materials - B.A.; Data Collection and/or Processing - A.E.; Analysis and/or Interpretation - E.E.; Literature Review - N.T.S., A.E.; Writer - A.E., N.T.S.; Critical Review - F.S., N.T.S.

Conflict of Interest: No conflict of interest was declared by the authors.

Financial Disclosure: The authors declared that this study has received no financial support.

\section{REFERENCES}

1. Hulme Moir M. Bartolo DC. Hemorrhoids. Gastroenterol Clin North Am 2001; 30: 183-197. [CrossRef]

2. Kartal N. Treatment methods in hemorrhodial disease. Türk Aile Hekimliği Dergisi 2002; 6: 121-126.

3. Barlas is. Stapled hemorrhoidopexy in advanced stage hemorrhoids: Short and long term results. Thesis: Istanbul Üniversitesi Cerrahpaşa Tıp Fakültesi Genel Cerrahi, 2008.

4. Cospite M. Double-blind, placebo-controlled evaluation of clinical activity and safety of Daflon $500 \mathrm{mg}$ in the treatment of acute hemorrhoids. Angiology 1994; 45: 566-573.

5. Ho YH, Foo CL, Seow-Choen F, Goh HS. Prospective randomized controlled trial of a micronized flavonoidic fraction to reduce bleeding after haemorrhoidectomy. Br J Surg 1995; 82: 1034-1035. [CrossRef]

6. Laughlan K, Jayne DG, Jackson D, Rupprecht F, Ribaric G. Stapled haemorrhoidopexy compared to Milligan-Morgan and Ferguson haemorrhoidectomy: a systematic review. Int J Colorectal Dis 2009; 24: 335-344. [CrossRef]

7. Smyth EF, Baker RP, Wilken BJ, Hartley JE, White TJ, Monson JR. Stapled versus excision haemorrhoidectomy: long-term follow up of a randomised controlled trial. Lancet 2003; 361: 1437-1438. [CrossRef]

8. Ammaturo C, Tufano A, Spiniello E, Sodano B, lervolino EM, Brillantino A, et al. Stapled haemorrhoidopexy vs. Milligan-Morgan haemorrhoidectomy for grade III haemorrhoids: a randomized clinical trial. G Chir 2012; 33: 346-351.

9. Sailer M, Bussen D, Debus ES, Fuchs KH, Thiede A. Quality of life in patients with benign anorectal disorders. Br J Surg 1998; 85: 1716-1719. [CrossRef]

10. Koçyiğit $H$, Aydemir Ö. Fişek G. Ölmez N, Memiş A. The reliability of SF-36 form in Turkish. Illaç ve Tedavi Dergisi 1999; 12: 102-106.

11. Fries JF, Singh G. The hierarchy of patient outcomes. Quality of Life and Pharmacoeconomics. In: Clinical Trials. 2nd ed. Philadelphia: Lippincott-Raven Publishers, 1996: 33.

12. Flanagan JC. A research approach to improving our Quality of Life. Am Psychocol 1978; 33: 138. [CrossRef]

13. Tiernan J, Hind D, Watson A, Wailoo AJ, Bradburn M, Shephard N, et al. The HubBLe trial: haemorrhoidal artery ligation $(\mathrm{HAL})$ versus rubber band ligation (RBL) for haemorrhoids. BMC Gastroenterol 2012; 12: 153. [CrossRef]

14. Riss S, Weiser FA, Riss T, Schwameis K, Mittlböck M, Stift A. Haemorrhoids and quality of life. Colorectal Dis 2011; 13: 48-52. [CrossRef]

15. Khan S, Pawlak SE, Eggenberger JC, Lee CS, Szilagy EJ, Wu JS, et al. Surgical treatment of hemorrhoids: prospective, randomized trial comparing closed excisional hemorrhoidectomy and the Harmonic Scalpel technique of excisional hemorrhoidectomy. Dis Colon Rectum 2001; 44: 845-849. [CrossRef]

16. Martinsons A, Narbuts Z, Brunenieks I, Pavars M, Lebedkovs S, Gardovskis J. A comparison of quality of life and postoperative results from combined PPH and conventional haemorrhoidectomy in different cases of haemorrhoidal disease. Colorectal Dis 2007; 9: 423-429. [CrossRef]

17. Czarzasty W, Kruszewski WJ, Zieliński J, Niżnik M. A one-year follow-up of the quality of life after stapled hemorrhoidopexy. Pol Przegl Chir 2011; 83: 204-211. [CrossRef]

18. Behboo R, Zanella S, Ruffolo C, Vafai M, Marino F, Scarpa M. Stapled haemorrhoidopexy: extent of tissue excision and clinical implications in the early postoperative period. Colorectal Dis 2011; 13: 697-702. [CrossRef]

19. Bussen D, Herold A, Bussen S. Health-Related Quality of Life after Surgical Haemorrhoid Treatment-Results, Methods and Problems. Zentabrl Chir 2012; 137: 385-389. 